\title{
Cine Amateur y Homecasting. Una mirada histórica a las visualidades contemporáneas
}

\begin{abstract}
Resumen
Este artículo presenta los resultados de un proyecto de investigación cuyo objetivo general fue reflexionar en torno a las características de la creación audiovisual amateur en la era digital, a partir de la revisión de variaciones y continuidades en el tiempo con respecto a las prácticas de producción no profesional con otros dispositivos como la fotografía y el cine. Las siguientes líneas se enfocan en un recorrido de ida y vuelta hacia el pasado y el presente que, a través de la interpretación dialéctica, permite establecer comparaciones entre características del desarrollo del cine amateur y la producción audiovisual amateur que circula en Internet o homecasting. Basado en la revisión documental y enmarcado en postulados provenientes de la historia cultural, los estudios visuales, los estudios culturales y la sociología de la tecnología, se concluye que en el panorama actual de producción audiovisual, esta comparación entre cine amateur y homecasting, más allá de señalar algunos elementos específicos, aporta a la necesaria indagación multidisciplinaria y a la inclusión de vectores como el histórico-cultural, para comprender, estudiar y enseñar de formas más críticas y complejas las visualidades contemporáneas.
\end{abstract}

\author{
Adriana M. Moreno Acosta \\ Doctora en Comunicación \\ Posdoctorado en el Programa de \\ Estudios Visuales CEIICH-UNAM. \\ Investigadora en la Universidad \\ Autónoma de Coahuila \\ Correo electrónico: \\ morenoadriana@uadec.edu.mx \\ ๑ orcid.org/0000-0001-6828-5397 \\ Google Scholar
}

Recibido: enero 16 de 2019 Aprobado: octubre 26 de 2020

\section{Palabras clave:}

cine amateur, homecasting, historia audiovisual, estudios visuales, Internet. 


\section{Amateur Cinema and Homecasting. A historical look at contemporary visualities}

\begin{abstract}
This article presents the results of a research project whose general objective was to reflect on the characteristics of amateur audiovisual creation in the digital era from the review of variations and continuities over time regarding non-professional production practices. with other devices such as photography and cinema. The following lines focus on a round trip to the past and the present that, through dialectical interpretation, allows establishing comparisons between characteristics of the development of amateur cinema and amateur audiovisual production that circulates on the Internet or homecasting. Based on the documentary review and framed in postulates from cultural history, visual studies, cultural studies and the sociology of technology, it is concluded that in the current panorama of audiovisual production, this comparison between amateur cinema and homecasting, beyond pointing out some specific elements, it contributes to the necessary multidisciplinary inquiry and the inclusion of vectors such as the historical-cultural vector, to understand, study and teach contemporary visualities in more critical and complex ways.
\end{abstract}

Key words: amateur cinema, homecasting, audiovisual history, visual studies, Internet. 


\section{Introducción}

El audiovisual amateur como tema de estudio, ha cobrado importancia en el panorama de la llamada convergencia de medios (Jenkins, 2008) gracias a aproximaciones que revisan tanto los procesos mismos de la producción audiovisual digital, como las formas comunicativas denominadas postmediaticas (Manovich, 2014) en donde términos como prosumidores (Toffler, 1980) o yousers (Van Dijck, 2007) han servido para nombrar a estos creadores no profesionales de contenidos para la web. Hoy en día con plataformas como YouTube, Instagram o Facebook, este tipo de piezas audiovisuales, parecieran gozar de vitalidad y protagonismo. Sin embargo, el Ilamado DIY (Do It Yourself) no comenzó con Internet y las computadoras. ${ }^{1}$ El audiovisual en Internet, responde a la convergencia histórica de formatos textuales, visuales, sonoros y audiovisuales, lo que trajo consigo la transformación hacia la cultura electrónica y el surgimiento de los llamados nuevos medios (Manovich, 2006). Este panorama nos exige un replanteamiento de categorías y modelos conceptuales y, a su vez, nos lleva a preguntarnos por las prácticas, esos procesos humanos que se repiten de manera cíclica para el uso y apropiación de dispositivos tecnológicos.

Las reflexiones que presenta este artículo tuvieron su origen en un proyecto de investigación posdoctoral que partió de un gran interrogante sobre cuáles eran las características de la producción audiovisual no profesional en la era digital y su relación con el pasado. De tal manera, se llevó a cabo una revisión documental cuyo objetivo general fue reflexionar en torno a la creación audiovisual amateur en la era digital a partir de la revisión de variaciones y continuidades en las prácticas realizadas por los no profesionales con dispositivos como la fotografía, el cine y el video, centrándose en dos de sus características específicas: en primer lugar, lo amateur en términos

'Una revisión se puede encontrar en este texto: https://doi.org/10.4995/aniav.2018.10052 
audiovisuales, entendido como construcción histórico-cultural; y, en segundo lugar, la técnica, específicamente el denominado lenguaje audiovisual, en lo que tiene que ver con las prácticas, sus transiciones y mutaciones en el tiempo, especialmente con el surgimiento de Internet como un enorme repositorio audiovisual.

\section{Enfoque metodológico}

El proyecto posdoctoral — del cual este texto se desprende- fue precedido por varios años de trabajo de campo exploratorio que revisó, bajo la triada sujeto-objeto-prácticas, casos específicos de producción audiovisual amateur en Internet a través de la observación flotante ${ }^{2}$. Allí comenzaron a surgir pistas acerca de las transformaciones en la visualidad y la representación, presentes en las prácticas audiovisuales no profesionales que tenían lugar en Internet, lo que hizo evidente la urgencia de revisar esas variaciones y continuidades en el tiempo, no con la intención de proponer teorías o parámetros universales, sino más bien desde la curiosidad por rastrear y comprender de formas más profundas, posibles relaciones entre los usos y apropiaciones que de los dispositivos audiovisuales hicieron los no profesionales en el pasado y el presente. Esta orientación del proyecto, exploratoria y de interpretación dialéctica, no busca elaborar resultados totalizadores sino abonar a la necesaria reflexión sobre los fenómenos audiovisuales contemporáneos; en su momento, ayudó también a cimentar una línea de investigación concreta denominada como: Internet, visualidades y vida cotidiana.

En términos generales, en el proyecto posdoctoral se buscó describir y analizar las características de la producción audiovisual amateur en la era digital centrándose en profundizar en tres aspectos.En un primer momento de la

\footnotetext{
2 Para una ampliación del uso de la observación flotante puede revisarse el texto: https://www.academia.edu/23142003/Observación_flotante_ como_herramienta_metodológica_para_el_estudio_de_producción_audiovisual_amateur_publicada_en_el_portal_YouTube
} 
revisión documental, el concepto de lo amateur fue rastreado en formas de producción audiovisual anteriores a Internet como la fotografía, el cine y el video. Para un segundo momento, se revisó (basado en la experiencia previa con el estudio de casos contemporáneos) la cuestión de la técnica, teniendo en cuenta las nuevas dinámicas para la producción audiovisual en Internet. Finalmente, se llegó a un tercer momento de análisis y profundización, el cual permitió poner en diálogo lo hallado bajo el vector de la historia cultural y la revisión documental, con planteamientos y posturas de los estudios visuales y la sociología de la tecnología, con la intención de avanzar hacia una reflexión que ayudara a profundizar la comprensión de estos fenómenos con un enfoque multidisciplinario y dentro de la línea de investigación propuesta, en el entendimiento de que los fenómenos de la producción audiovisual amateur tienen profundas relaciones e implicaciones con la cultura visual contemporánea y esta, a su vez, con las visualidades y regímenes escópicos (Jay, 1988; Mitchell, 1994) que le precedieron.

Este ejercicio permitió dar cuenta de variaciones y continuidades en la producción audiovisual amateur, a través de un análisis diacrónico y sincrónico, generándose así interpretaciones dialécticas que a través de una constante alternancia entre la descripción/análisis aportaron perspectivas sobre estos fenómenos contemporáneos y permitieron dimensionar la profundidad y complejidad del campo en el que tiene lugar la pregunta acerca de la aparentemente banal producción audiovisual amateur en Internet. Bajo la premisa de que es necesario comprender este fenómeno asumiéndolo no sólo como una práctica de producción y comunicación, sino como un fenómeno cultural que ha transformado históricamente las experiencias estéticas y los concesos colectivos acerca de la visualidad, resultaba indispensable explorar cómo la introducción de un dispositivo que permite producir imágenes a los no expertos, da lugar a apropiaciones tanto de conocimientos técnicos, como de 
herramientas expresivas y de representación, potenciadas por la apropiación de la técnica y favorecidas por la introducción de discursos para su uso.

El presente artículo, presenta aspectos específicos hallados en el ejercicio amplio de reflexión descrito anteriormente, concentrándose en torno a variaciones y continuidades referentes al cine amateur y el homecasting. ${ }^{3}$ Se propone un recorrido entre el pasado y el presente, describiendo características focalizadas, para reconocer algunos de los lazos que unen estos dos procesos de apropiación de dispositivos tecnológicos y de producción audiovisual, lo que permite enfatizar en que es necesario revisar la historia para comprender de manera más crítica los fenómenos actuales de producción y la participación, ligados al uso habitual de tecnologías para registrar imágenes y sonidos. La primera parte del texto presenta un recorrido histórico sobre el cine amateur, que avanza hacia la puesta en perspectiva de características del pasado y el presente, lo que permite, en el apartado técnica y discurso, revisar conexiones con respecto a los procesos de uso y apropiación de los dispositivos y enfatizar en la relevancia de pensar en el estudio del audiovisual en Internet desde cruces complejos, para reflexionar, en sintonía con los estudios visuales, en las prácticas y los procesos individuales y colectivos, como vector que enmarca regímenes escópicos, los cuales se construyen en el tiempo a través de consensos sobre la visualidad, la visibilidad y sus formas de enunciación.

\section{Cine amateur: apuntes históricos}

Entender Cine e Internet como dispositivos implica asumirlos como entramados socioténicos complejos (Aibar, 1996) en los cuales se cruzan relaciones de poder y de saber, en contextos espaciotemporales diferenciados. Cine e Internet, tienen muchos elementos comunes: ambos hicieron el tránsito de una tecnología ligada en un principio a experimentos científicos, para convertirse 
en objetos de consumo, en un espectáculo de participación masiva y finalmente en un placer que sirve a la idea tecnocrática del progreso (Punt, 2000). Desde esta perspectiva, tanto el cine como el Internet, pueden entenderse como una convergencia de discursos, invenciones e innovaciones, impulsados por el advenimiento tecnológico, con interpretaciones y reinterpretaciones constantes a través de la historia, lo que permite dar cuenta de procesos sociales que permanentemente son atravesados por la técnica.

Sabemos que el cine como dispositivo de producción audiovisual surge gracias a un largo proceso de hallazgos y experimentaciones que dieron lugar a la creación de diversas máquinas que precedieron a la cámara de cine: fantascopio, zootropo, estroboscopio, cronofotógrafo, entre otras. La descomposición del movimiento, especialmente la del galope del caballo llevado a cabo por Muybridge entre 1878 y 1881, es a menudo citada como uno de los experimentos que dio origen a la cinematografía. Thomas Alva Edison inventó la película dentada de $35 \mathrm{~mm}$, la cual hacía posible el "arrastre". Dicha película fue fabricada a partir de 1889 por la casa Eastman Kodak de Rochester, en donde se producían las ya famosas cámaras de fotografía Kodak de bajo costo. Poco tiempo después de realizar las primeras proyecciones públicas de cine, la familia Lumière, inmersa desde antes en la industria de la fotografía, envío operadores de cámara entrenados a distintos lugares del mundo para filmar y luego proyectar frente al público esas imágenes en movimiento, lo que dio origen a un espectáculo nuevo en el cual miles de personas se apiñaban en salas oscuras (Sadoul, 2004). El cine se convirtió rápidamente en lo que Gubern (1969) describió como el "encuentro de la máquina con la cultura" pues, según el autor, el cine junto con la fotografía ensancharon el horizonte visual de los hombres creando una "civilización de la imagen para las masas".

La cámara de cine fue una máquina para producir imágenes con unos elevados costos de producción y, por lo tanto, su uso a mayor escala estaba 
directamente relacionado con la posibilidad de fabricación y distribución comercial, es decir, la compra y venta del objeto mismo a un precio menor. Por tal motivo, la historia registra que el cine amateur, en el cual un número más amplio de personas pudo participar y producir, no despegó ni se convirtió en un segmento de mercado importante para los fabricantes de cámaras hasta la estandarización del formato $16 \mathrm{~mm}$, en la década de $1920^{4}$.

La casa Eastman Kodak de Rochester, no sólo era el lugar en donde se fabricaba la película de $16 \mathrm{~mm}$, sino que fue espacio para la experimentación de los propios empleados de la compañía y sus familias, quienes comenzaron a explorar las posibilidades de las nuevas cámaras de cine de tamaño más reducido. Cuando el primer prototipo de la cámara de $16 \mathrm{~mm}$ se terminó, se invitó a las esposas de algunos empleados de la compañía, sin ningún conocimiento previo de su manejo, para que hicieran películas; esto con el fin de poner a prueba la facilidad de operación de las cámaras que pronto se comercializarían, dirigidas principalmente al segmento de las amas de casa. Las películas hechas por estas mujeres serían luego usadas en presentaciones de la marca y como publicidad del nuevo producto (Swanson, 2003). La idea de que la madre hiciera pequeñas películas de sus hijos como recuerdos para la posteridad, se planteó con insistencia a través de la publicidad de Kodak. Durante este periodo del Siglo XX, se introduce también el término "Home movies" para designar a las películas hechas en casa por las familias acomodadas y con la intención de preservar los que se presentaban en el discurso de introducción del dispositivo, como importantes momentos familiares. Este terreno ya estaba trabajado previamente por los discursos de uso de la cámara fotográfica, pero podía seguir siendo explotado ahora por la cámara de cine portátil. Se trataba de películas producidas dentro del dominio de lo privado y a menudo elaboradas con una cronología de "tiempo real", es decir, con muy poco

${ }^{4}$ Cabe señalar, que los registros de la expansión y el uso de estos dispositivos refieren principalmente a los lugares geográficos en los cuales el aparato era fabricado y que, de Latinoamérica, por ejemplo, no se encontraron registros tan sistemáticos sino hasta después de la mitad del siglo veinte. 
trabajo de edición. Hay que señalar también que, hasta entonces, las mujeres no tenían mucha participación como directoras de cine ni como fotógrafas profesionales; sus roles principales estaban ligados a ser modelos para las fotografías y/o actrices en las películas, lo que quiere decir que incluir a las amas de casa y a los niños hacía parte del discurso necesario para involucrar a más miembros de la familia en la producción de imágenes y, de esta manera, promover el objeto-cámara fuera del ámbito de los expertos e introducirlo como indispensable en la vida privada y familiar.

Hacia 1932 apareció el mucho más económico formato de $8 \mathrm{~mm}$, que definitivamente permitió un gran impulso para las ventas de cámaras de cine (Szczelkun, 2000). Sin embargo, y aunque el invento de los nuevos formatos significó una reducción de más del $50 \%$ en costos de fabricación de la película, la producción casera usando 16 u 8mm, seguía siendo un lujo que sólo podían pagar las clases altas. En la publicidad de la década de los años veinte y treinta, Kodak hizo un gran énfasis en filmar a la familia: las vacaciones, los niños jugando, como recuerdos que debían preservarse; estos eventos comenzaron a construirse desde la publicidad y la prensa como el objetivo de la producción de cine no profesional y como parte necesaria de su estética, en lo que Zimmermann (1988) describe como una clara colonización discursiva. La Segunda Guerra Mundial fue otro momento idóneo para explotar el potencial de las cámaras de cine en formatos pequeños. En esta época se tiene registro de un buen número de documentos y noticieros cinematográficos hechos por aficionados (Szczelkun, 2000). En el ámbito de lo familiar, se consolidaba el discurso de registrar la vida cotidiana para compartirla luego con los que en ese momento no estaban presentes. De nuevo, las mujeres jugaron un papel relevante para el establecimiento de roles y usos del dispositivo.

También en Estados Unidos la popularización de cine con película de $16 \mathrm{~mm}$ propició que muchos amateurs intentaran imitar las condiciones de producción 
de los profesionales. El periodo de 1923 a 1940 es crucial para comprender las formas en las cuales la industria del cine introdujo nuevos discursos, creando claros límites para los aficionados. En el verano de 1926 se tiene registro de la primera reunión de la Liga Amateur de cineastas en Nueva York (Askari, 2009), la cual fue un punto de partida fructífero para la enseñanza y el crecimiento en general del cine amateur en Estados Unidos. Los registros históricos muestran que detrás de la organización de estas reuniones estaban presentes los intereses económicos de Kodak, pues, como ya había sucedido con la fotografía, existía un interés comercial en masificar el cine amateur bajo ciertos estándares. Para 1927 ya existían clubes de "Movie Makers" en once estados de los Estados Unidos, lo que no tardó en llamarse el movimiento de cine amateur norteamericano. La Amateur Cinema Ligue contaba con instalaciones para producir películas, así como con un comité de expertos revisores, a los que sus miembros podían enviar para ser evaluados, sus guiones o material ya filmado (Swanson, 2003). En este caso, el crecimiento de revistas especializadas en cine jugó un papel fundamental al definir buena parte de lo que sería el "estilo profesional", ligado a lo que Zimmermann (1988) nombra el estilo Hollywood. Esta exaltación para que lo amateur imitará lo profesional, permitió con el tiempo ubicarlo también en un segundo plano, estableciendo una jerarquía en la que lo profesional tenía mucho más valor que lo amateur, pues este ultimo era visto como una copia, un mero intento por emular.

No puede perderse de vista que durante la primera mitad del Siglo XX, el cine de Hollywood fue posicionado como el ideal de perfección técnica audiovisual, asociado a estereotipos de belleza y a ciertos valores familiares (Zimmermann, 1988), por lo que también los asuntos técnicos se hicieron cada vez mas complejos, lo que permitió a las marcas que estaban vendiendo más cámaras caseras, incursionar en el mercado de la venta de accesorios para la producción no profesional: lentes, trípodes y equipo de iluminación para los aficionados. Sin embargo, dentro del movimiento del cine amateur también 
existían voces que creían que la experimentación podía permitirles a estos creadores entender de manera no sólo estética si no ética el cine (Swanson, 2003), lo que los llevó a realizar proyectos que desafiaron la hegemonía de las prácticas culturales más comerciales.

En el periodo de la posguerra, y específicamente en Estados Unidos, el aumento de la riqueza en las familias y la expansión de la vida suburbana permitió que para 1952 un 6\% de las familias tuvieran en su casa una cámara de cine; para la década de los sesenta, cámaras de $8 \mathrm{~mm}$ de diversas marcas y precios - dirigidas a la producción casera- estaban disponibles en el mercado (Szczelkun, 2000). Hacia 1965 se introdujo en la industria cinematográfica el formato super 8, que permitió que bajaran aún más los costos para la producción de cine no profesional. Los registros mas importantes de producción cinematográfica amateur en Latinoamérica datan justamente de los años sesenta y setenta del Siglo XX con el uso de formatos como el super 8 (Gómez-Mantecón, 2012; Orell-García, 2006).

Entrada la segunda mitad del Siglo XX, un gran salto en la masificación de las prácticas para producir audiovisual no profesional llegaría con la introducción de las cámaras portátiles de video, particularmente el formato Handycam en la década de los ochenta. Sin embargo, los usos dados a estos aparatos hicieron que siguieran ampliamente ligados a las memorias familiares. En el Siglo XXI, son notables las cifras de penetración y uso de teléfonos móviles con cámara incorporada. En Latinoamérica se esperaba que para el año 2020 se usaran 577 millones de smartphones 5 . A pesar de las denominadas "brechas en el acceso", tanto a aparatos como a conectividad, un número mucho mayor de personas, incluso en los llamados países en desarrollo, tienen acceso a un teléfono con cámara incorporada y puede usar, aunque sea de forma

Informe con proyecciones hecho en 2016: https://www.gsma.com/latinamerica/wp-content/uploads/2016/09/ME_LATAM_2016_English_Web_ Singles_R-1.pdf 
esporádica, alguna conexión a Internet, lo que los convierte en potenciales creadores audiovisuales.

Este breve recorrido busca señalar algunas persistencias entre las posibilidades técnicas y el acceso, las cuales hicieron posible la producción audiovisual no profesional; también permite señalar una inevitable conexión histórica entre los aparatos, los intereses de mercado y la vida cotidiana. Estos apuntes nos permiten pensar en resonancias históricas para los estudios acerca de la cultura visual contemporánea, particularmente en lo referido a las transformaciones en la producción, la distribución y el consumo audiovisual no profesional o amateur.

\section{Todos podemos hacer películas}

De manera similar a como sucedió con la fotografía (Moreno-Acosta, 2016), las diferencias entre el profesional y el amateur —en el caso del cine a principios del Siglo XX - estaban asociadas a cuestiones del tamaño de los equipos para filmar y a la logística necesaria para hacerlo. El ritual de la proyección de las películas caseras en la sala oscura dentro casa, como parte de una reunión familiar, era un momento primordial del proceso de socialización y, por lo tanto, del discurso de uso. Para la fotografía se había establecido ya un ritual parecido: reunirse con familia y amigos a ver los álbumes de fotos. Este momento de visualización se diferenciaba con el de ir al cine pues, en el caso de las películas caseras, el público era más activo, ya que éstas eran comentadas en tiempo real y un ambiente mucho menos silencioso y solemne que el de la sala de cine (Szczelkun, 2000).

Actualmente, con el uso de los dispositivos individuales y portátiles para el registro, los valores asociados a la visualización de materiales audiovisuales son otros y están menos cercanos a la "conversación" sobre las imágenes, a 
las historias detrás del registro y mucho más al número de likes. Hoy en día, el visionado personal en una pequeña pantalla hace innecesario el ritual de reunirse a ver las imágenes, pues las reuniones ahora son virtuales y asincrónicas. Muchos de nosotros llevamos un aparato en el que podemos reproducir para enseñar a otros un video divertido, el registro personal de un evento familiar o un mensaje grabado en audio o video. En este sentido, tenemos más volumen de producción y de acceso, pero no necesariamente establecemos conexiones o relaciones profundas con esos materiales audiovisuales, como sí podría pensarse, por ejemplo, para el caso de los álbumes fotográficos en papel, o las películas caseras en cinta, los cuales tenían una condición material de piezas únicas. Como lo afirma Prada (2015), en Internet, la producción audiovisual es más procesual y colaborativa, lo que parece generar —en su mayoríasituaciones comunicativas más que objetos o relaciones.

En el inicio del cine amateur, la valoración de la producción estaba en manos de quienes escribían columnas de periódicos y revistas especializadas, en las cuales se abordaba el tema del escaso valor técnico y artístico de las películas caseras y lo tedioso que resultaba su visionado: el carrete de corta duración, aproximadamente cuatro minutos, la cámara que simplemente seguía los movimientos del ojo del operador, la falta de planificación e intenciones narrativas y la poca edición del material final, fueron algunos de los elementos que para los expertos hacían a las películas caseras productos inferiores y de poco mérito (Szczelkun, 2000). Artículos de prensa abordaban temas como los "errores comunes en las películas caseras" y daban consejos para mejorar los resultados finales bajo los estándares del momento, de manera muy parecida a lo que hacen hoy en día los tutoriales para realizadores audiovisuales en programas como el YouTube Partners. Por el contrario, para el audiovisual en Internet, la asunción de lo banal y cotidiano pareció asumirse como algo natural, de hecho, a inicios del Siglo XXI, portales como Vine ganaron fama al promover y popularizar videos caseros de muy corta 
duración (6 segundos) cuyas cualidades técnicas no eran excepcionales y cuyo contenido estaba ligado en su mayoría a la categoría de "video divertido": caídas, coreografías fallidas, golpes. No debemos olvidar que, para el caso del video en Internet, los repertorios están nutridos también de lo visto en la televisión, por ejemplo, los programas de videos caseros divertidos o los reality shows, pueden considerarse un antecedente directo de estos temas, más cercanos a lo individual y lo cotidiano. Sin embargo, pareciera también que en distintos momentos históricos y con diversos aparatos, los neófitos productores audiovisuales han usado su propia vida — al puro estilo de los hermanos Lumiere - para explorar y para familiarizarse con el aparato y la técnica (Moreno-Acosta, 2015). Los resultados de los procesos de apropiación y uso de los dispositivos, para producir imágenes en movimiento por parte de los no expertos, tendrían históricamente cierta estética compartida en la cual la narrativa no es tan importante. Lo significativo es el espectáculo de la vida cotidiana, que constituye la excusa perfecta para explorar y aprender a usar el dispositivo.

Hoy en día, las cámaras parecieran omnipresentes. Están en los teléfonos, en los autos, en las calles; así que para hacer películas ni siquiera sería necesario mucho equipo o una cámara costosa. La producción audiovisual se sugiere actualmente como fácil y al alcance de la mano; pareciera también que no son necesarios muchos conocimientos para grabar un video divertido o lograr que un video sea viral. En la producción cotidiana de imágenes digitales prima la idea del registro sobre la idea de archivo, pues las capacidades reproductivas y transformadoras de lo digital han modificado toda la cadena de producción, distribución y consumo de imágenes, tanto fijas como en movimiento. La imagen electrónica trajo consigo el surgimiento de grandes plataformas y repositorios de información textual, visual, sonora, y de datos. Bucles digitales como los gifs, son señuelos que aparecen ante los ojos del flaneur digital y que de alguna forma nos llevan a los inicios del cine, a una idea muy básica 
de la imagen en movimiento, cuya función era la de atrapar temporalmente la atención distraída (Prada, 2015). Prácticas con las que ya había experimentado el cine en película y el video en cinta, en Internet son posibles al instante, pues el metraje puede ser encontrado en línea sin mayores inconvenientes; estos remixes, mash-ups, son parte fundamental de las formas en las cuales hoy en día se crean piezas audiovisuales. Los fragmentos ya no tienen un único autor y pueden ser utilizados y re-versionados a la manera del snippet ${ }^{6}$ en programación. Mas recientemente, la realidad virtual, la transmisión en vivo y el video en $360^{\circ}$, están transformando formalmente la representación audiovisual de lo real, constituyéndose en ejercicios de visión que parecieran sobrepasar lo humano, por lo que valdría la pena preguntarnos si estamos reflexionando lo suficiente sobre esas transformaciones en las formas de ver y en los modos de hacer archivo y visualidad.

Rosalind Williams (2003), experta en la historia de las tecnologías, afirma que el auge de la tecnología como entretenimiento, en la última parte del siglo XX, marcó un alejamiento en la participación de muchos ciudadanos en la ciencia, orillándolos más bien hacia un consumo pasivo de sus resultados como espectáculo y como un producto de consumo; un desplazamiento en donde el contrato entre el usuario y la tecnología es a la vez complejo y contradictorio. Este consumo pasivo de resultados transformados en espectáculo (viajes espaciales, automóviles autónomos, robots etc.), es decir, la construcción de la tecnología como un producto de consumo (teléfonos, tabletas, relojes, infinidad de gadgets tecnológicos), propició la popularización de un ideal de estilo de vida en donde la tecnología no se asocia a lo científico, sino al consumo y el ocio. Así las cosas, una vez que fueron del dominio público (cine o Internet) estos artefactos culturales han sido usados en una variedad de formas, algunas incluso subversivas, pero en su mayoría asociadas a placeres que podríamos

${ }^{6}$ El término snippet hace referencia a una parte reutilizable de código fuente que circula y puede ser usada por múltiples usuarios para facilitar procesos de escritura de código de programación. 
denominar más frívolos. Esta afirmación es relevante, pues actualmente, los usuarios de los dispositivos no están fascinados con la cuestión tecnológica del aparato, que es bastante compleja en términos de la ciencia necesaria para lograr que funcione, sino que la relación primordial que se establece, en este caso ante la posibilidad de generar contenidos audiovisuales propios, está más integrada con placeres banales que invisibilizan otros elementos y que terminan siendo más importantes y, por lo tanto, dominan la experiencia de uso.

Una importante continuidad a lo largo del Siglo XX, está en que los discursos de la publicidad fueron muy bien aprovechados por empresas como Kodak y resultaron trascendentales para introducir una idea que permea hasta nuestros días: la de la "experiencia de uso", basada en lo emotivo, en la creación de subjetividades y que pareciera ha acompañado el establecimiento de los modelos de uso de los dispositivos para producir imágenes y sonidos, a nivel no profesional, hasta nuestros días. Esta persistencia nos habla del poder de lo visual y lo audiovisual para generar sentidos y de la importancia de estudiar y analizar en el tiempo estos procesos, lo que permite constatar cómo la técnica es efectivamente un proyecto histórico-social.

\section{Técnica y discurso}

La reflexión amplia por la técnica ha ocupado a grandes pensadores a lo largo de la historia, pues los desarrollos tecnológicos transforman la experiencia social. Si asumimos, siguiendo a Habermas (1986), que la técnica es un proyecto histórico-social en el que siempre hay un propósito de dominio metódico, científico, calculado y calculante, tanto de la naturaleza como de los hombres, comprenderemos también por qué, históricamente, las imágenes han sido utilizadas como arma política e ideológica. Vale la pena recordar que la primera escuela en donde se estudiaron técnicas cinematográficas 
se fundó en la Unión Soviética en 1919 con el nombre de VGIK (Instituto Pansoviético de Cinematografía) y que, en Italia, Mussolini fundó hacia 1935 el "Centro Experimental de Cinematografía", mientras que, en la España franquista, hacia 1947, se creó el "Instituto de Investigaciones y Experiencias Cinematográficas". En este sentido, no es un secreto que el cine (y podríamos decir que el audiovisual en general) ha sido utilizado en distintos contextos como herramienta para promover e instaurar ciertos comportamientos, valores y modos de vida (Girona, 2015). Normas y consensos creados, modulados y construidos culturalmente, constituyen un poder que establece criterios y valores audiovisuales, los cuales, como puede verse en distintos momentos y para distintas tecnologías de producción de imágenes, han ejercido un control social de normalización para las posibilidades de la representación visual y audiovisual.

Esta administración y gestión de los significados ha estado presente a lo largo de la historia de uso de los dispositivos y no es para nada inocente, pues permite establecer reglas formales, así como convenciones narrativas y técnicas, que estandarizan y diferencian claramente tipos de producciones, por ejemplo, profesionales y amateurs, estableciendo valoraciones sociales, deseos y ámbitos de consumo para uno u otro tipo de producción.

Para la producción audiovisual en Internet, hoy en día, podemos identificar códigos técnicos y culturales ampliamente promovidos hasta el punto de generalizarse en pautas formales y de contenido. Basta ver la "evolución" hacia la estandarización —en portales como YouTube- de géneros como el confesional (Wesch, 2009) en el que básicamente vemos a una persona que habla directamente a la cámara en un plano cerrado y desde un espacio íntimo como su habitación. Es fácil identificar estilos (en cuanto a ángulos de cámara, edición y hasta lenguaje) que han sido impuestos por los videos exitosos en Internet y que muchos usuarios imitan con la intención de obtener 
beneficios. Por ejemplo, un programa como Partners de YouTube, en donde uno de los requisitos indispensables para acceder es tener como mínimo 100.000 suscriptores $^{7}$. Lo anterior permite reforzar la idea de que, en el caso de la producción audiovisual no profesional, en cada periodo y para cada dispositivo tecnológico se han construido tanto repertorios audiovisuales como discursos de uso y apropiación, aprovechados por los intereses comerciales para terminar siendo ampliamente aceptados e imitados.

En el caso del cine amateur, este control sobre el discurso, ejercido entre otros a través de la publicidad, permitió en su momento a los intereses dominantes definir y crear las fronteras para las prácticas de la producción audiovisual. Así, durante buena parte del Siglo XX, compañías como Kodak o Sony introdujeron discursos específicos de uso para aparatos como las cámaras de cine y video portátil. Hoy en día, con la imagen digital y para comprender cómo se introducen estos discursos de uso, podemos remitirnos a lo que Brea (2007) denominó como una constelación extendida de industrias del ocio y el entretenimiento, las cuales establecen pautas y estándares para las interacciones virtuales y, por lo tanto, para el uso y producción de materiales textuales, visuales y sonoros; todo ello, columna vertebral de lo que el autor define como capitalismo cultural electrónico (e-cK), en donde la producción visual y audiovisual, en la medida en que irrumpe en la vida cotidiana de millones de personas, no tiene ya tanto que ver con el arte y la estética sino que implica transformaciones que afectan, por ejemplo, la economía global, pues todos los contenidos están monetizados. Lo anterior engrana a la perfección con estas mutaciones actuales de los modelos económicos, en donde en la vida en red y las industrias de la experiencia, son protagonistas debido a la fusión entre comunicación, diseño y entretenimiento. 
Así, en las mal llamadas "sociedades del conocimiento", lo central no es el saber en sí mismo, sino la capitalización de la información (Moraza, 2012). El modelo actual de la producción de contenidos audiovisuales no profesionales en Internet no está basado en la escasez, como sucedía en el mercado del arte con la figura de un único autor y su obra. En este caso, no hay restricción en el acceso a un único original o a pocas copias escasas y por lo tanto muy caras; por el contrario, el creador aficionado tiene hoy en día una ventaja, que radica en la posibilidad de distribución masiva de sus producciones, sin que ello atente contra sus propios intereses, como sí solía pensarse para el caso de los artistas (Prada, 2015). Recordemos que la remuneración, para muchos de estos productores de contenidos en Internet, es más simbólica y tiene que ver con el reconocimiento y la fama.

En las últimas décadas, y con el ascenso de los nuevos modelos de negocio en Internet, la tarea del cuidado y diseño del yo se ha tornado fundamental, tanto, que ya no podemos hablar de registro y/o contemplación desinteresada de imágenes, pues estamos frente al ascenso de discursos en donde el autodiseño es requisito para posicionarse socialmente y establecer una narrativa personal (Groys, 2016). Se trata de una profunda variación en el sentido de la experiencia estética contemporánea, en donde lo sublime pareciera ser necesariamente autoreferencial (Brea, 1991). En cuanto a los temas y contenidos de la producción audiovisual no profesional actual, se trata en su gran mayoría de procesos auto-narrativos que dan cuenta de un interés en la imagen propia que construimos y ofrecemos a otros, procesos que además se miden mucho más en términos cuantitativos de velocidad y alcance, que en términos cualitativos o reflexivos.

Los procesos de producción audiovisual no profesional tuvieron un importante giro técnico durante el siglo XX con el surgimiento del formato de video y las cámaras tipo handyCam, y otro gran cambio con la producción audiovisual 
digital posible con teléfonos portátiles conectados a Internet. Sin embargo, el borramiento de las distancias entre el profesional y el amateur ha tenido que ver históricamente más con una pérdida de recursos (técnicos, formales, logísticos) por parte de los profesionales, que con un empoderamiento masivo de los amateurs (Gómez-Cruz, 2007). En el caso del cine amateur, los registros parecieran mostrarnos que quedó marginado al ámbito de los recuerdos, experimentaciones con poco mérito o copias aficionadas del estilo Hollywood, y que los no profesionales no exploraron lo suficiente en su valor social y estético. El balance no es para nada alentador, pues la revisión documental sugiere que históricamente las modulaciones y discursos de uso han logrado suprimir, para este tipo de usuarios, mucho de las posibilidades de exploración del lenguaje audiovisual, desdibujando así su potencial emancipador y como medio expresivo. Hoy en día, los contenidos audiovisuales en las redes sociales virtuales e incluso programas de capacitación como los ofrecidos por YouTube Partners, alientan también procesos de estandarización de los contenidos a través del discurso de colaboración con los productores no profesionales para que sus canales sean exitosos, es decir: producir a través de fórmulas aceptadas lo que el público quiere ver. En este sentido, el surgimiento de estéticas particulares de lo amateur en Internet que, al igual que con otros dispositivos y en otras épocas, en un principio encarnaron posibilidades para expresiones de tipos muy diversos, terminaron también en la era digital, convirtiéndose en estilos más bien homogenizados, con un repertorio limitado de opciones narrativas y de montaje, ligado principalmente al tono de comedia e imitado actualmente por aquellos que sueñan con la fama y la fortuna de un YouTuber.

\section{Tecnología / amateur}

No debemos perder de vista, entonces, que los procesos de popularización de tecnologías que conllevan el uso y apropiación de nuevos aparatos como las cámaras y/o las computadoras, tienen que ver con procesos sociales 
y económicos que modelan y definen usos y estilos dominantes de dichas tecnologías al propiciar renegociaciones de las maneras como se utilizan estos inventos una vez que son de dominio público (Punt, 2000).

En el caso del cine amateur o del homecastig en Internet, podríamos afirmar que el invento se convirtió en la base de una experiencia cultural masiva con un sentido de uso específico y socialmente construido. Procesos parecidos han sucedido con otras máquinas que se incorporaron en la vida cotidiana de los seres humanos. Por ello, es importante señalar que tal vez no se ha discutido suficiente sobre la estrecha relación que existe entre estos ámbitos: el de la popularización de un aparato tecnológico que debe comercializarse, es decir, venderse, y cuya incorporación a la vida social implica la introducción y generalización de ciertos discursos y, por otro lado, los específicos procesos de introducción, apropiación y uso del dispositivo que se construyen. Este vector es fundamental, pues sabemos que, por ejemplo, en el caso de la historia del cine, se suele dar prioridad en los estudios e investigaciones a la reconstrucción a través del recuento cronológico, basado en un desglose y valoración de los recursos técnicos y formales de las películas, así como en el análisis y evaluación del uso del Ilamado lenguaje audiovisual, con un marcado interés, heredado de las artes, en el binomio de autor y obra. Este énfasis está presente también en las formas de enseñanza y aprendizaje más tradicionales de la historia del audiovisual, en donde no siempre se tienen en cuenta los procesos culturales, que engloban matices económicos y políticos y que hacen que el estudio de los usos de las tecnologías para producir imágenes sea, especialmente en la actualidad, mucho más complejo que un recuento de fechas, títulos y autores.

A medida que se ahonda en la historia del audiovisual, ligada a la historia de la tecnología que lo hizo posible y a los usos que de esta tecnología hicieron las personas, sin perder de vista la introducción de ciertos discursos, el cine amateur 
o el homecasting en Internet ya no parecen más el resultado inevitable de una necesidad expresiva para generar imágenes en movimiento o información que conecte a las personas, sino que podemos comenzar a entenderlos también como la intersección de una compleja red de discursos e interacciones que se construyen a partir de un buen número de dispositivos y tecnologías (Punt, 2000), como un complejo entramado sociotécnico que, por supuesto, sirve a propósitos específicos. Si asumimos entonces que históricamente la representación visual y audiovisual no podría entenderse como mera ciencia aplicada al desarrollo de una máquina capaz de capturar y reproducir imágenes en movimiento, pero tampoco y de forma exclusiva, como un arte expresivo que recurre a formas idealizadas de la representación asociadas a las fórmulas clásicas de la estética, hablaremos entonces, para el caso de las producciones no profesionales actuales, de formas quizás más cercanas a la experiencia de lo cotidiano, la auto-representación y la configuración de un yo público.

Se considera que incluir en el estudio del audiovisual estas aproximaciones, cercanas a postulados de los Estudios Visuales y la Sociología de la Tecnología, permiten que sea posible plantearnos preguntas en términos de la historia cultural acerca de las tecnologías, los dispositivos y las construcciones sociales que estos propician. Por lo tanto, revisitar la historia de las tecnologías, permite proponer múltiples enfoques para entenderlas como una construcción social que ha generado sentidos a través de la interacción continua entre los individuos, los aparatos, las prácticas y, por supuesto, los intereses de grupos socialmente dominantes. 


\section{Conclusiones}

Manovich (2006), en su propuesta para reconstruir una arqueología de los medios, afirma que distintas tecnologías en diferentes momentos históricos han permitido un proceso continuo en el cual se convierten los objetos en signos móviles. Al respecto, al revisar los procesos históricos, pareciera que el control social sobre la representación audiovisual ha sesgado las posibilidades de lo amateur, relegándolo una y otra vez al ámbito de lo doméstico, como una afición para ser compartida con familia y amigos o, de manera más reciente, como una actividad relacionada con la construcción de un yo público y no como una práctica compleja de producción de puntos de vista y capacidades de agencia. Algunos de los elementos a destacar como resultado de la revisión documental e interpretación dialéctica, que se presentan a manera de cierre, se exponen a continuación.

Actualmente, en la producción cotidiana de imágenes digitales en Internet, prima la idea del registro sobre la del archivo. Los valores asociados a la visualización de materiales audiovisuales parecieran ser menos cercanos a la conversación sobre las imágenes y se centran en una relación de intercambio y comunicación en tiempo real. Asuntos técnicos como que los dispositivos sean individuales y portátiles, la posibilidad de generar un gran volumen de producción, así como la facilidad no sólo para grabar sino para editar y borrar, han hecho que no necesariamente se establezcan conexiones densas y profundas en el tiempo con los materiales audiovisuales de elaboración propia.

Por otra parte, y al contrario de otros momentos históricos, para el audiovisual en Internet, la asunción de lo banal y cotidiano pareció asumirse como algo positivo y natural. Las producciones audiovisuales en Internet no buscaron imitar los estándares profesionales de predecesores como la televisión o el cine, lo que permitió que se explorara y explotara a partir incluso del desconocimiento 
de los usuarios del Ilamado lenguaje audiovisual. Estas exploraciones de los no profesionales fueron creando estéticas y formas narrativas como las que vemos hoy en día en estilos particulares de puesta en escena usados por los YouTubers. Cabe resaltar que los usuarios de los dispositivos tampoco están necesariamente familiarizados con asuntos científicos o tecnológicos complejos del aparato. En este sentido, la experiencia de uso es dominada por el discurso de la facilidad para ver y mostrar, apelando a lo emotivo y a la construcción de subjetividades colectivas, por lo que los discursos están centrados en el autodiseño, requisito para posicionarse socialmente y establecer una narrativa personal en Internet; de esta forma, mucho de la experiencia estética contemporánea pareciera ser principalmente autoreferencial.

En cuanto a la construcción de particulares auto-narrativas, que en un principio se pudieron pensar como puerta de entrada para la diversidad en la representación —rápidamente y como en otros momentos históricos- fueron delimitadas a parámetros específicos de imágenes y sonidos aceptados y, por lo tanto, repetidos por múltiples usuarios, aunque en espacios geográficos diversos. De forma que, si los desarrollos tecnológicos transforman la experiencia social y las imágenes han sido utilizadas históricamente como arma política e ideológica, es indispensable seguir ampliando un diálogo interdisciplinario sobre cómo los dispositivos tecnológicos contemporáneos establecen modos de ver y hacer visualidades, así como examinar con mirada crítica la introducción y validación de discursos específicos en cuanto al uso, es decir, estar atentos para advertir y desvelar el control social de normalización —que no es nuevo y que sigue presente- para las posibilidades de la representación visual y audiovisual en Internet.

Finalmente, las puntadas entre el pasado y el presente expuestas en este texto entre el cine amateur a lo largo del Siglo XX y el homecasting como fenómeno actual en Internet, permitieron puntualizar algunos aspectos. Sin embargo, 
una vez terminado el proyecto de investigación, fue claro que la principal conclusión del ejercicio de revisión e interpretación dialéctica era señalar la relevancia de una exploración multidisciplinaria, abogando por la inclusión de vectores como el histórico-cultural para comprender, estudiar y enseñar - en sentidos mas complejos y profundos - los fenómenos actuales de la visualidad. Por todo ello, es relevante insistir en que los estudios, las investigaciones y la enseñanza del audiovisual, abran sus perspectivas más allá de los recuentos cronológicos, el análisis formal o semiótico y se incorporen vectores relacionados con la sociología y la historia cultural para, así, dimensionar el amplio espectro de la producción audiovisual contemporánea como lenguaje y herramienta expresiva, pero también en su carácter de construcción social de subjetividades.

Habermas (1986) nos recuerda, siguiendo a Marcuse, que la fusión de técnica y dominio implica un proyecto material instrumentalizado y racional. Romper este circulo supondría otro proyecto, más emancipador y por lo tanto reflexivo, al que estaríamos llamados docentes e investigadores, que tendría que incluir una revisión de la historia de los hechos y las ideas para complejizar y comprender mejor los fenómenos técnicos del presente. Por lo tanto, es necesario el optimismo, pero también la pausa. Como usuarios de los dispositivos tecnológicos deberíamos tener las herramientas, no sólo materiales sino reflexivas, para decidir transitar — cuando sea necesario- de la expresión personal y privada a la construcción consciente de documentos visuales y audiovisuales con objetivos públicos y políticos concretos. Llegar a este punto no requiere únicamente de una "alfabetización", esa sería una postura reduccionista, pues lo indispensable estaría mas relacionado con propiciar, en una sociedad atravesada por modelos de producción de información y conocimiento en formatos textuales, visuales y sonoros, procesos reflexivos amplios, colectivos e interdisciplinarios, acerca de lo que significan las imágenes y la visualidad como construcciones histórico-culturales. De ahí la importancia 
de abordar estos asuntos, desde la perspectiva de los giros Icónicos / pictóricos (García-Varas, 2011) y la historia, pues este enfoque permite evidenciar también los cambios y permanencias en los sentidos de la visualidad, así como su ineludible relación con procesos económicos, tecnológicos y culturales. Por lo tanto, resulta indispensable fomentar desde diversos escenarios tanto la mirada crítica como la producción informada, pues, como en otros momentos, a la par de la normalización deben surgir voces que reten a las prácticas dominantes de la visualidad, lo que hace urgente estudiar más allá de la celebración y los lugares comunes la producción audiovisual amateur actual, para ahondar y reflexionar sobre las manifestaciones contemporáneas de la visualidad, incluyendo sus matices políticos, de control y poder, lo que nos permitiría asumir — de manera más consiente, en individual y en colectivo- nuestro papel como productores de contenidos audiovisuales en la sociedad en red.

\section{Referencias}

Aibar, E. (1996). La vida social de las máquinas: orígenes, desarrollo y perspectivas actuales en la sociología de la tecnología. Reis, 76(96), 141-170. http://www.reis.cis.es/REIS/PDF/REIS_076_09.pdf

Askari, K. (2009). Early 16mm Colour by a Career Amateur. Film History, 21(2), 150-163. http://www.jstor.org/stable/40406020

Brea, J. L. (1991). Las auras frías. El culto a la obra de arte en la era postaurática. Barcelona: Editorial Anagrama.

Brea, J. L. (2007). Cultura RAM: Mutaciones de la cultura en la era de su distribución electrónica. Madrid: Gedisa Editorial.

García Varas, A. (2011). Filosofía de la imagen. Salamanca: Ediciones Universidad de Salamanca. 
Gómez Cruz, E. (2007). De la cultura Kodak a la imagen en Red. Barcelona: UOC Press.

Gómez Mantecón, A. (2012). El cine super 8 en México (1970-1989). México: UNAM, Filmoteca.

Girona, R. (2015). El Cine de propaganda en EE. UU. Barcelona: Editorial UOC.

Groys, B. (2016). Volverse Publico. Las transformaciones del arte en el ágora contemporánea. Buenos Aires: Caja Negra Editora.

Gubern, R. (1969). Historia del Cine. Barcelona: Editorial Anagrama.

Habermas, J. (1986). Ciencia y Tecnología como ideología. Madrid: Letra e.

Jay, M. (1988). Scopic regimes of modernity. In Foster, H. (Ed.), Vision and visuality (pp. 3-28). Seattle: Bay Press.

Jenkins, H. (2008). Convergence Culture. La cultura de la convergencia de los medios de comunicación. Barcelona: Ediciones Paidós.

Manovich, L. (2006). El Lenguaje de los Nuevos Medios de Comunicación. La imagen en la Era Digital. Madrid: Paidós.

Manovich, L. (2014). Post-Media Aesthetics. In M. Kinder \& T. McPherson (eds.), Transmedia Frictions. The Digital, the Arts, and the Humanities. Oakland: University of California Press.

Moreno Acosta, A. M. (2015). Homecasting: Ecos del pasado, dualidades del presente. Memorias del XXVII Encuentro Nacional Asociación Mexicana de Investigadores de la Comunicación AMIC 2015. Universidad Autónoma de Querétaro, México. https://www.academia.edu/22696676/Homecasting Ecos_del_pasado_dualidades_del_presente 
Moreno Acosta, A. M. (2016). Fotografía amateur: la construcción cultural de un rol. Revista Comunicación, 34(1), 23-38. https://revistas.upb.edu.co/ index.php/comunicacion/article/view/6768

Moraza, J. L. (2012). El arte en la era del capitalismo cognitivo. Jornadas de El arte en la Sociedad del Conocimiento, organizadas por la Sección de Artes Plásticas y Monumentales de la Sociedad de Estudios Vascos. Facultad de Bellas Artes de la Universidad del País Vasco.

Mitchell, W. J. T. (1994). The Pictorial Turn. In Pictorial Theory: Essays on Verbal and Visual Representation (pp. 11-34). Chicago, University of Chicago Press.

Orell García, M. (2006). Las Fuentes del Nuevo Cine Latinoamericano. Valparaiso: Ediciones Universitarias Pontificia Universidad Católica de Valparaiso.

Prada, J. M. (2015). Practicas Artísticas e Internet en la Época de las Redes Sociales. Madrid: AKAL.

Punt, M. (2000). Parallel Histories: Early Cinema and Digital Media. Convergence: The International Journal Of Research Into New Media Technologies, 6(2), 62-76. https://doi.org/10.1177\%2F135485650000600205

Sadoul, G. (2004). Historia del Cine Mundial. México: Siglo XXI Editores.

Swanson, D. (2003). Inventing amateur film: Marion Norris Gleason, Eastman Kodak and the Rochester scene, 1921-1932. Film History, 15, 126-136. http://www.jstor.org/stable/3815505

Szczelkun, S. (2000). The Value of Home Movies. Oral History, 28(2), 94-98. http://www.jstor.org/stable/40166863

Toffler, A. (1980). The Third Wave. New York: Bantam Books. 
Van Dijck, J. (2007). Television 2.0: YouTube and the Emergence of Homecasting. University of Amsterdam, Media in Transition International Conference, MIT. Amsterdam.

Wesch, M. (2009). Users Like You: Theorizing Agency in User-Generated Content. Media, Culture And Society, 31(1), 41-58.

Williams, R. (2003). Retooling: A Historian Confronts Technological Change. Massachusetts: The MIT Press.

Zimmermann, P. R. (1988). Professional Results with Amateur Ease: The Formation of Amateur Filmmaking Aesthetics 1923-1940. Film History, 2(3), 267-281. https://www.jstor.org/stable/3815121

Cómo citar: Moreno-Acosta, A. M. (2021). Cine Amateur y Homecasting. Una mirada histórica a las visualidades contemporáneas. Revista KEPES, 18(23), 243-271. https://doi.org/10.17151/kepes.2021.18.23.9 